\title{
Ciência na prisão: educação não formal e a formação inicial docente no contexto prisional
}

\author{
Science in prison: \\ non-formal education and initial teacher formation in the prison
} context

Marina Savordelli Versolato Universidade Federal de São Paulo marinasversolato@gmail.com

Ana Paula Moreira Alves Universidade Federal de São Paulo anapaula.moreiraalves@gmail.com

Emerson Izidoro Universidade Federal de São Paulo emerson.izidoro@unifesp.br

\begin{abstract}
Resumo: A Banca da Ciência $(\mathrm{BC})$ é uma proposta de intervenções não formais de comunicação dialógica e crítica da ciência. O objetivo desse artigo é investigar os processos interativos no âmbito da difusão científica em espaços de educação não formal - no caso, a Banca da Ciência - entre os mediadores e os educandos jovens e adultos privados de liberdade. Para tanto observamos o processo interativo, no decorrer de duas apresentações da BC, entre os mediadores e o público da Educação de Jovens e Adultos (EJA) privados de liberdade utilizando, para registro, diário de campo e fotos. Também foram promovidos dois grupos de discussão com os mediadores. Com base nas teorias de Vigotski e Freire verificamos, na análise dos dados, indícios objetivos de que a atividade da BC contribuiu com a formação dos mediadores, que são futuros professores, fazendo-os pensar sobre as especificidades do trabalho com o público da EJA.
\end{abstract}

Palavras-chave: Educação não formal. Educação de Jovens e Adultos. Educação nas prisões. Formação Inicial docente.

\begin{abstract}
The Stand of Science (SS) is a proposal for non-formal interventions of dialogical and critical communication of science. The purpose of this article is investigate the interactive processes within the scope of scientific outreach in non-formal educational spaces - in this case, the Stand of Science - between mediators and young and adult students deprived of their liberty. We observed the interactive process, during two SS presentations, between the mediators and the students of Youth and Adult Education (YAE) deprived of liberty using, for registration, board diary and photos. Two discussion groups were also promoted with the mediators. Based on the theory of Vigotski and Freire, we verified, in the analysis of the data, objective evidence that the activity of SS contributed in the mediators formation, who will become teachers, making them think about the specificities of working with the public of YAE.
\end{abstract}

Key-words: Non-formal education. Young and Adult Education. Education in prisons. Initial Teacher formation. 


\section{Introdução}

A iniciativa Banca da Ciência (BC), que vem sendo desenvolvida há cerca de uma década por professores da Universidade de São Paulo e da Universidade Federal de São Paulo (UNIFESP), apresenta uma proposta interdisciplinar de intervenções não formais de comunicação dialógica e crítica da Ciência para diversos públicos em diferentes espaços sociais, incluindo os educativos escolar e não-escolar, buscando, assim, favorecer o processo de popularização e democratização do conhecimento científico. Para isso, o projeto dispõe de espaços de difusão científica montados em estruturas de banca de jornal, uma dessas localizada no campus Guarulhos da Unifesp. Além das Bancas fixas buscou-se encontrar um formato simples e suficientemente versátil para ser empregado em diversas situações e espaços, composto de cavaletes e tampos padronizados, o que permitiu uma maior mobilidade das atividades da Banca da Ciência. (PIASSI et al., 2013)

A BC tem como uma de suas preocupações a formação dos mediadores para atuação nos processos interativos de difusão científica. As atividades desenvolvidas dialogam com os cursos de licenciatura da Universidade Federal de São Paulo, bem como das outras instituições envolvidas, e têm importante valor formativo profissional para os estudantes, contribuindo com a formação dos futuros professores.

A aprendizagem dos indivíduos, na perspectiva histórico cultural, depende de todas as suas interações em diferentes ambientes. As interações que acontecem em espaços de educação não formal, como a BC também contribuem diretamente para o processo de aprendizagem, tanto dos visitantes como também dos mediadores, que são futuros professores.

\section{A educação não formal e a educação de jovens e adultos}

Difícil definir uma data de origem para os processos de educação não formal, especialmente por esta não estar necessariamente vinculada a instituições, mas abranger experiências em diferentes práticas sociais. Porém, autores como Trilla (2008) afirmam que a educação não formal começou a expandir-se significativamente, e ser reconhecida como uma modalidade educacional, a partir da segunda metade do século XX. Obviamente esse conceito não surge de uma geração espontânea ou isolada, mas sim em decorrência de diversos fatores sociais, econômicos e tecnológicos que, por um lado originam novas necessidades educacionais e, por outro, suscitam 
inéditas possibilidades pedagógicas não escolares que buscam satisfazer essas demandas. (TRILLA, 2008,)

Segundo Gohn (2011) a educação tem sido proclamada como uma das áreas-chave para enfrentar os novos desafios desenvolvidos pela globalização e pelo avanço tecnológico na era da informação. É chamada também para superar a miséria do povo, buscando promover o acesso dos excluídos a uma sociedade mais justa e igualitária. Nesse cenário, observamos uma ampliação do conceito de Educação, que não se restringe mais aos processos de ensino-aprendizagem dentro das escolas e instituições formais, transpondo os muros da escola. A educação é um fenômeno complexo, multiforme, disperso, heterogêneo, permanente e quase onipresente. Existe educação na escola, na família, mas ela também se verifica nas bibliotecas e nos museus, na internet, tv etc. Como são diversos os conjuntos de processos que convencionalmente chamamos "educacionais", é preciso, para continuar abordando-os com algum sentido, começar a distingui-los uns dos outros. Temos então os conceitos: educação formal e não formal. Faz-se necessário aqui explanar rapidamente sobre o conceito de educação não formal:

A educação não-formal não tem o caráter formal dos processos escolares, normatizados por instituições superiores oficiais e certificadores de titularidades. Difere da educação formal porque essa última possui uma legislação nacional que normatiza critérios e procedimentos específicos. A educação não-formal lida com outra lógica nas categorias espaço e tempo, dada pelo fato de não ter um curriculum definido a priori, quer quanto aos conteúdos, temas ou habilidades a serem trabalhadas. (GOHN, 2014, p.47)

Considerando a diversidades de espaços, tempo e as possibilidades que a educação não formal apresenta, ela pode ser uma ferramenta importante no processo de formação e construção da cidadania das pessoas, bem como de sua aproximação dos conhecimentos científicos sistematizados, em qualquer nível social ou de escolaridade, destacando-se, entretanto, sua relevância no campo da educação de jovens e adultos. Pelo fato ser mais flexível e interativa, geralmente consegue atingir a atenção e o imaginário dos educandos. (GOHN, 2014).

Sendo assim, quando os alunos têm a oportunidade de visitar espaços de educação não formal, a atividade pode contribuir para a superação de possíveis resistências dos educandos, sobretudo os da Educação de Jovens e Adultos, em relação a determinados conteúdos curriculares, uma vez que se aproximam dos temas científicos do cotidiano e que são apresentados de formas diversas.

Cabe aqui ressaltar, conforme afirma Trilla (2008), que é certo que a educação não formal está longe de ser a solução milagrosa para os problemas da realidade educacional atual ou futura. 
Se não for em uma perspectiva dialógica e problematizadora, a educação não formal pode ser tão classista, alienante, estática e uniformizada quanto a formal. Apresentar a educação não formal como remédio e solução para as desigualdades educacionais e sociais e para os vícios em que a escola formal muitas vezes cai é tão simplista quanto recusar sua colaboração para facilitar o acesso mais amplo e justo a uma educação de maior qualidade e para todos.

\section{Banca da Ciência no presídio}

Foram realizadas duas atividades de intervenção da Banca da Ciência na Penitenciária Masculina José Parada Neto, em Guarulhos. Cada uma delas contou com a participação de aproximadamente 100 educandos das turmas de ensino fundamental e médio, da modalidade EJA da unidade escolar instalada na penitenciária. A primeira aconteceu no dia 8 de outubro de 2018 e a segunda no dia 30 de agosto de 2019. Os experimentos científicos apresentados na intervenção pertencem ao acervo da $\mathrm{BC}$ e foram selecionados pelos mediadores e coordenadores do projeto.

Com relação às especificidades do público da EJA, não devemos, por receio de uma suposta invasão cultural, negar aos educandos, que em grande número pertencem a camadas mais populares, acesso ao conhecimento científico sistematizado. Cabe aqui destacar também que não devemos reduzir ou limitar o acesso ao conhecimento acumulado ao longo da história. As aprendizagens instrumentais, sobretudo na sociedade da informação, são imprescindíveis para romper o ciclo de exclusão. (AULBERT et al, 2018). Freire (1999) relata:

Se os grupos populares desconhecem de forma crítica como a nova sociedade
tecnológica funciona, certamente devido às condições precárias em que foram
sendo proibidos de ser e de saber, a saída não pode se dar através da propaganda
ideológica e de uma divulgação massiva de conhecimentos científicos. Mas,
encontra-se no diálogo e no intransigente respeito ao conhecimento do outro.
(FREIRE, 1999, p.118)

A iniciativa BC com a EJA privados de liberdade visou proporcionar a difusão científica de maneira interativa e dialógica, aproximando assim os educandos do conhecimento científico. Por isso, frisou-se muito, com os mediadores, a necessidade de estabelecer uma comunicação dialógica com os educandos para que o acesso ao conhecimento não se desse por meio de uma invasão cultural. FREIRE (2018) critica as ações antidialógicas: 
Entre as várias características da teoria antidialógica da ação, nos deteremos em uma: a invasão cultural. Toda invasão sugere, obviamente, um sujeito que invade. Seu espaço histórico-cultural, que lhe dá sua visão de mundo, é o espaço de onde ele parte para penetrar outro espaço histórico-cultural, superpondo aos indivíduos deste seu sistema de valores. (FREIRE, 2018, p. 48)

Freire (2018) afirma também que, normalmente, os invasores buscam descaracterizar a cultura invadida, romper seu perfil, enchê-la inclusive de subprodutos da cultura invasora. Para o autor a manipulação e conquista (expressões da invasão cultural) não é caminho para libertação e sim para dominação de uma cultura sobre a outra. Enquanto mediadores que pensam a educação e o acesso ao conhecimento em uma perspectiva libertadora, não podemos rejeitar, em qualquer nível, a problematização dialógica. É justamente por meio dessa perspectiva dialógica que acreditamos ser possível um trabalho de difusão científica aproximando ciência e sociedade, lembrando sempre que o diálogo efetivo e verdadeiro não pode ser construído em uma via de mão única. É necessário estar atendo para não cair em práticas depositantes de um falso saber, que anula o espírito crítico, serve à domesticação dos homens e instrumentaliza a invasão cultural. O que devemos buscar é a comunicação. (FREIRE, 2018).

O que caracteriza a comunicação enquanto este comunicar comunicando-se é que ela é dialógica, assim como o diálogo é comunicativo. [...] É então indispensável ao ato comunicativo, para que este seja eficiente, o acordo entre os sujeitos, reciprocamente comunicantes. (FREIRE, 2018, p. 87)

Ponderando que os educandos da EJA são pessoas que tiveram trajetórias escolares bastante turbulentas, buscamos promover um processo interativo atrativo e a mediação foi realizada com o intuito de aproximá-los do conhecimento científico, considerando suas vivências e saberes. Para isso o diálogo foi fundamental durante todo o processo. As ações educativas, sejam elas formais, informais ou não formais, devem consistir em comunicação. A educação é comunicação, é diálogo, na medida em que não é a transferência de saber, mas um encontro de sujeitos interlocutores que buscam a significação dos saberes. (FREIRE, 2018).

\section{Banca da Ciência e a formação dos mediadores}

A Banca da Ciência atua na difusão científica de forma interativa e dialógica com a intenção de aproximar seus participantes do conhecimento científico. Esse processo interativo tem efeitos tantos nos visitantes como nos mediadores, de forma análoga ao que afirma Freire (2017) sobre a relação docente-discente: 
Não há docência sem discência, as duas se explicam e seus sujeitos, apesar das diferenças que os conotam, não se reduzem à condição de objeto um do outro. Quem ensina aprende ao ensinar e quem aprende ensina ao aprender. Quem ensina, ensina alguma coisa a alguém. (...) Ensinar inexiste sem aprender e viceversa, e foi aprendendo socialmente que, historicamente, mulheres e homens descobriram que era possível ensinar. (FREIRE, 2017, p. 25)

Freire relata que o processo de ensino e aprendizagem, e aqui inferimos que, mesmo quando acontece em espaço de educação não formal, tem efeitos tanto sobre os educandos quanto nos educadores, uma vez que os humanos são seres histórico-culturais que aprendem e se desenvolvem na relação com o meio e com o outro.

Desta maneira, o educador já não é o que apenas educa, mas o que, enquanto educa, é educado, em diálogo com o educando que, ao ser educado também educa. (FREIRE, 2016, p. 120)

Concordando com as contribuições de Freire, pensamos nos processos interativos da BC e o processo de mediação, salientando sempre a importância do diálogo. Quando essa relação se dá por meio do diálogo ambos aprendem, os visitantes e os mediadores. O nosso processo interativo, ao propor a aproximação dos mediadores com os educandos da EJA nesta perspectiva dialógica, contribuiu para que os mediadores e os visitantes apreendessem. Sobre a questão da mediação no processo de difusão científica Cazelli et al (2003) discorrem:

Pesquisas em museus de ciência sobre os saberes da mediação - entendidos como os diferentes conhecimentos e práticas sociais presentes no ato de mediar a relação entre a ciência e o público, nos seus aspectos científico, cultural e social estão começando a ser desenvolvidas, evidenciando a necessidade de investir na formação específica do quadro profissional daqueles que atuam nas atividades educativas. (CAZELLI et al, 2003, p.8)

A BC tem também como umas das suas preocupações a formação dos mediadores que atuam nos processos interativos. Buscamos sempre pontuar a importância dessa mediação. As atividades de difusão científica desenvolvidas possuem relacionam-se com os cursos de graduação da universidade e representam importante valor formativo profissional para os estudantes dessas diversas áreas contribuindo, em especial, com a formação dos futuros professores. Para além de serem mediadores, os graduandos participaram de conversas e orientações para pensar e definir quais experimentos seriam apropriados para o público em questão e refletiram também sobre qual seria o tipo de postura a ser utilizar na intervenção. 
Nesse sentido, além de buscar colaborar com a reflexão sobre a qualidade social da educação ofertada para jovens e adultos, a BC está inserida no processo de formação docente, notadamente destacando a diversidade do público da EJA e as possibilidades de elaboração de estratégias didático-pedagógicas a fim de atender as especificidades de tempo e espaço na oferta desta modalidade.

Freire (2017) convida-nos, também, a refletir sobre a importância de saber escutar, quando propomos um processo interativo na perspectiva dialógica, principalmente para os mediadores.

[...] quão importante é saber escutar. Se, na verdade, o sonho que nos anima é democrático e solidário, não é falando aos outros, de cima para baixo, sobretudo, como se fôssemos os portadores da verdade a ser transmitida aos demais, que aprendemos a escutar, mas é escutando que aprendemos a falar com eles. (FREIRE, 2017, p. 111)

Saber escutar é o que permite um processo educativo democrático, solidário e dialógico. A escuta faz parte do diálogo. E deve, portanto, ser um conteúdo essencial no processo de formação dos educadores. Não há exercício do diálogo sem o exercício da escuta, nem sem o silêncio como uma atitude fundamental no espaço da comunicação, pois é escutando que se aprende a falar. (FREIRE, 2017). Por essa razão é possível identificar a escuta como um caminho, uma atitude, saber da formação pedagógica docente. A disponibilidade permanente à escuta, em Freire, é um princípio, um conteúdo da formação humana e profissional. Em nosso processo de formação dos mediadores, frisamos a importância da escuta, uma escuta ativa e respeitosa que permite de fato o diálogo.

Um assunto que também teve destaque, no trabalho de planejamento com nossos mediadores, foi à importância de considerar os visitantes, que nesse caso eram educandos da EJA, como sujeitos com saberes, vivências e conhecimentos.

Sobre a formação docente o autor Nóvoa (2017) aponta para a necessidade de formarmos professores para uma profissão. Ele destaca que, na atualidade, tem ganhado força um discurso de desvalorização da figura do professor e que, mais do que nunca, se tem a precisão de considerar que ser professor é uma profissão. Existe a necessidade de pensar sobre a formação profissional dos professores, isto é, uma ideia que parece simples, mas que define um rumo claro: a formação docente, tanto inicial quanto a continuada, deve ter como matriz a formação para uma profissão. 
Quando chamamos a atenção para essa profissionalização docente, buscamos sair do campo da "caridade" e da filantropia e entrar no campo do direito. Sobre isso trazemos as contribuições de Galvão e Di Pierro (2007):

Por isso a importância de reafirmar, aqui, que a alfabetização e a educação ao longo da vida constituem um direito e não uma filantropia, realizada por alguns educadores de "boa vontade". Ao lado de práticas educativas que atendam a esse público sem estigmatizá-lo, é preciso, também, realizar um esforço coletivo para a formulação de políticas públicas que ultrapassem o espírito das campanhas, estendam a oferta de ensino a essa população para as etapas posteriores à alfabetização, tornando-se, assim, permanentes e, de fato, integrantes do sistema educacional do país. (GALVÃO; DI PIERRO, 2007, p. 100)

A educação é um direito e o estado deve garantir uma educação de qualidade para todos. Assim, garantir que os educandos tenham bons professores entra no campo do direito e não da caridade. Para Arroyo (2017), vincular o direito da EJA à educação nos direitos humanos é um caminho para sairmos de reducionismos de que a EJA é apenas para suprir percursos escolares truncados. $\mathrm{Na}$ visão reducionista, justifica-se a não necessidade de profissionais específicos para trabalhar na EJA. Qualquer docente que "domine” as habilidades escolares servirá. Essa visão supletiva tem sido responsável pela ausência de profissionais com formação específica para a garantia de direito dos educandos jovens e adultos.

Ao propormos, aos mediadores, a possibilidade da vivência do processo interativo de difusão científica, com os educandos da EJA, buscamos propor uma reflexão sobre as especificidades desse público.

O texto das Diretrizes Curriculares Nacionais para a EJA indica:

O preparo de um docente voltado para a EJA deve incluir, além das exigências formativas para todo e qualquer professor, aquelas relativas à complexidade diferencial desta modalidade de ensino. Assim esse profissional do magistério deve estar preparado para interagir empaticamente com esta parcela de estudantes e de estabelecer o exercício do diálogo. (BRASIL, 2000, p.56)

Aparentemente o contato com a realidade acaba sendo mais um espaço para formar os professores, em especial os da EJA. O que justifica a necessidade e importância de ações como a nossa no processo de formação inicial docente. O que propusemos nessa pesquisa foi o contato com a realidade da EJA e para, além disso, nosso grupo de discussão propôs tratar dialogicamente algumas questões referentes ao processo interativo e as especificidades dessa modalidade. 


\section{Procedimentos metodológicos}

Para investigar os processos interativos, vivenciados em uma perspectiva histórica e do movimento, a pesquisa foi desenvolvida em três etapas: a primeira, antes do processo interativo, nas reuniões onde foram definidos, com os mediadores, quais experimentos científicos seriam interessantes e apropriados para o público da EJA. A segunda etapa foi a observação direta dos processos interativos da $\mathrm{BC}$ com o público específico da EJA privados de liberdade, ocasião em que utilizamos como ferramentas de registro um diário de campo e fotos do processo interativo. A terceira, e última, etapa da coleta de dados consistiram na realização dos dois grupos de discussão com os mediadores da BC para retomar e refletir sobre os processos interativos vivenciados.

Participaram do nosso grupo de discussão os mediadores, que são graduandos dos cursos de licenciaturas da Unifesp e a pesquisadora como mediadora. Foram feitos registros em vídeo dos grupos de discussão posteriormente transcritos, mantendo a literalidade das falas, com o intuito de identificar as significações dos participantes para análise do processo interativo.

A partir dos dados coletados nos grupos de discussão realizamos uma análise estruturada, por meio dos núcleos de significação, tendo em vista não apenas a descrição do fenômeno, mas também sua análise e explicação em sua totalidade. Segundo Aguiar et al. (2006) são duas as categorias que compõem as significações: sentido e significado, possibilitando acesso a elementos da subjetividade do sujeito, no caso da investigação proposta, sobre os processos interativos vivenciados pelos mediadores da BC com os educandos da EJA privados de liberdade.

Os núcleos de significação possibilitam fazer uma análise, a partir das falas, que seja coerente com os princípios teóricos metodológicos da teoria Histórico Cultural. Essa proposta pretende instrumentalizar o pesquisador no processo de apreensão das significações a partir das falas dos sujeitos, diante da realidade com a qual se relaciona. Para além do empírico é uma análise dialética que ultrapassa o campo das aparências. Assim, buscando ir além das palavras (significados) para sua dimensão subjetiva (sentidos).

\section{Análise e interpretação dos resultados.}

Segundo Freire (2016) o educador, ao trabalhar com o público da EJA, deve buscar estabelecer uma relação horizontal com os educandos, ou seja, uma relação de troca e diálogo. É justamente por meio dessa perspectiva dialógica que acreditamos ser possível um trabalho de 
difusão científica na EJA. Cabe aqui destacar que nossos mediadores observaram que, ao propor uma relação interativa e dialógica com os educandos, ambos se beneficiaram. Essa relação horizontal que Freire (2016) aborda foi observada em algumas falas:

Ninha: Teve uma hora que a gente colocou o dominó na mesa e eles mesmo mostravam coisas que eles sabiam para gente.[...]Ai e parece que eles ficaram bem interessados, pelo menos foi o que eu falei assim, na minha mesa tinha muita gente e foi legal porque é uma troca de informações.

Mesmo essa concepção sendo considerada, observamos em algumas falas, que eles ficaram surpresos ao perceber que os educandos tinham, de fato, conhecimentos científicos, inclusive sobre alguns assuntos sabiam mais do que eles. Nesse sentido, apontamos para importância de vivenciar, aproximar-se da realidade para que se possa conhecer, de fato, e não apenas reproduzir estigmas e determinações sociais. Freire (2018) afirma que a tomada de consciência, como uma operação própria do homem, resulta da sua defrontação com o mundo e com a realidade concreta.

Cristine:[...] a gente aprendeu muita coisa com eles também eles falavam coisa que a gente nem sabia... [...] Ele deu uma aula pra gente sabe[...] tinha um outro também que foi e falou que ele já tinha trabalho foi a usina eólica, que nós fizemos né e ele já trabalhou numa usina e que ele sabe então acrescentou muito para gente.

A fala da Cristine ressaltam a importância do contato com a realidade para perceber que, de fato, eles possuem conhecimentos, superando algumas determinações sociais. Galvão e Di Pierro (2007) apontam que, muitas vezes, os sujeitos com baixa escolaridades, como os educandos da EJA, são vistos como "ignorantes" por não terem o conhecimento sistematizado da maneira convencional. A experiência aqui analisada buscou evidenciar os saberes construídos por pessoas com baixa escolaridade, e aponta a possibilidade de troca de conhecimento entre educandos e mediadores. Sabe-se que os educandos da EJA possuem diversos saberes prévios, tal como aparece na seguinte fala:

Lourdes: O entendimento deles de tudo. Não só de mundo, mas da área científica. Porque o que a gente fala, o que a gente pensa muito ah, igual quando o Paulo Freire tá falando já tá falando só de visão de mundo, mas a gente tá falando de ciência também de conhecimento produzido que eles sabem, mesmo que tenham sido barrados a eles, eles tem outras formas de saber eu acho que é isso.

Aqui cabe ressaltar como o contato com a EJA trouxe essa ressignificação sobre os educandos para os nossos sujeitos. Para que isso acontecesse foi necessária uma postura dialógica 
por parte de ambos. Os dados suscitam ainda uma reflexão sobre a relação da escolha do experimento científico pensando na especificidade do público.

Luísa: Porque querendo ou não eles já são adultos e sabem, e acho que levar algo muito simples ou muito bobo, poderia acho que eles se sentiram mal, tipo assim: "nossa a gente não é capaz, será que a gente é capaz só disso"?

É interessante o respeito que os mediadores tiveram com os educandos, considerando que, por eles serem adultos, não deviam ser infantilizados e não queriam que eles sentissem que fosse algo muito simples. Antes da intervenção, nas orientações para os mediadores, destacamos algumas especificidades da EJA, como a importância de respeitar seus saberes. Com relação à fala da Luísa, pontuamos que os educandos da EJA, em sua maioria, vivenciaram, no passado, uma trajetória escolar turbulenta e por isso, muitas vezes, apresentam uma baixa autoestima. O que pode ser ainda agravado pela situação de privação de liberdade. Interessante o olhar atento de Luísa em escolher algo para que eles se sentissem capazes. Com relação ao público da EJA, muitas vezes podemos notar na fala dos próprios educandos que pensam não serem capazes de aprender. Observa-se que, em geral, é um público que tem baixa autoestima e culpabilizam-se pelo seu "fracasso" escolar:

Me lembro de seus olhos azuis marejados de lágrimas expressando seu sofrimento e a assunção da culpa pelo seu "fracasso" no mundo. Pessoas assim fazem parte da legião de ofendidos que não percebem a razão de ser de sua dor na perversidade do sistema social, econômico e político em que vivem, mas na sua incompetência. Enquanto sentirem assim, pensarem assim e agirem assim, reforçam o poder do sistema. Se tornam coniventes da ordem desumanizante. (FREIRE, 2017, p.81)

Os determinismos levam a um reducionismo que tenta explicar, pelo viés orgânico, essas assimetrias que são construídas histórica e socialmente. E, muitas vezes os próprios sujeitos, vítimas destes determinismos, acreditam neles. Cabe então aos educadores que atuam com o público da EJA ter esse cuidado e esse olhar para evitar reforçar esses estigmas e determinismos.

Ao analisarmos qual foi à impressão dos mediadores sobre os educandos privados de liberdade trazemos as contribuições de Freire (2018) que destaca o fato de sermos sujeitos históricos. Como sujeitos históricos não podemos ser compreendidos fora de nossas relações com o mundo. Ele afirma que devemos reconhecer que somos seres condicionados, ou seja, que refletimos determinações históricas sociais. Para Freire (2017) devemos reconhecer que a história é tempo de possibilidade e não de determinismo. Na perspectiva histórico cultural entendemos o preconceito como uma produção humana, estabelecida nas relações sociais como um processo 
histórico. (BUENDGENS e CARVALHO, 2016). Temos também a fala da Luísa que estão carregadas dessa visão determinista:

Luísa: $\mathrm{Na}$ realidade assim quando eles entraram a gente não esperava muito. [...] Mas eles super de boa, eles respeitaram, eles não chegaram em cima. Eles vieram com tempo, não avançaram sabe? Eles ficaram na deles até a gente ir chamando, até eles sentirem que eles estavam sendo chamados pra participar...

No começo do excerto, Luísa mostra que não esperava nada dos educandos, já no segundo ela diz que foi tudo tranquilo, que eles respeitaram e no meio da frase expressa o sentido do que de fato quis dizer, ao afirmar que eles não avançaram. O avançar tem um sentido carregado de determinismo social referente aos sujeitos privados de liberdade, como se eles fossem perigosos, violentos e sem controle. Segundo Graciliano e Haddad (2015) sabe-se que, historicamente, as prisões brasileiras sempre se aproximam muito mais da ideia de punição e de depósito de seres humanos que não sabem "conviver” em sociedade. E é essa a visão acabou aparecendo nas falas de Luísa.

Galvão e Di Pierro (2007) relatam que, ao longo da história do Brasil, foi-se fabricando um discurso preconceituoso sobre os educandos da EJA. A construção do estigma em relação a esse público deve ser compreendida quando situada em relação a sociedade e determinados tempos. O preconceito não é, portanto, nem natural nem universal, é socialmente construído. Segundo Aubert et al. (2018), temos uma relação hierárquica de conhecimento presente na nossa sociedade, ligada ao conceito tradicional de inteligência, que exclui pessoas pelo simples fato de não terem seguido uma trajetória escolar tradicional.

Refletindo sobre o papel dos mediadores no processo interativo, o quanto é importante que tenham uma postura dialógica e convidativa para que os visitantes interajam com os experimentos científicos. Trazemos as contribuições de Cazelli et al (2003) que apontam para a relevância do papel da mediação. Conforme referido pelas autoras, é de extrema importância conhecer o público e considerá-lo na hora de pensar o processo interativo, pois baseado em suas especificidades, é possível pensar desde que experimentos levar e até mesmo qual postura os mediadores devem usar no processo interativo. Sobre isso temos a seguinte fala:

Cristine: [...]o meu sentimento assim olhando eles, analisando eles e eu achei neles, como elas falaram, no começo eu achei eles assim bem retraídos tal e se soltando aos poucos e conforme a gente foi conversando explicando os experimentos a gente foi vendo que eles foram se soltando e eles tinham assim uma reação de uma gratidão muito grande com a gente sabe, de a gente tá ali da gente tá enxergando eles como igual sabe? Como ser humano e eu achei isso para 
eles muito forte sabe, essa gratidão deles sentirem isso. Eu achei isso daí muito forte.

Nesse trecho ficou claro como o papel do mediador fez a diferença na qualidade do processo interativo, para que os visitantes se sentissem à vontade para explorar os experimentos. Freire (2016) afirma a necessidade de o educador considerar os educandos como sujeitos ativos no processo de ensino e aprendizagem, estabelecendo uma relação dialógica que permita que se expressem e busquem relacionar os conceitos abordados com o seu cotidiano. Ter um olhar atento para quem são os sujeitos e uma escuta ativa para o que eles te trazem de informação durante o processo interativo.

Ainda em relação às representações sociais sobre a população carcerária, os depoimentos dos mediadores revelam construções sociais que legitimam a violação dos direitos educativos e culturais a este grupo:

Lourdes: [...] assim no senso comum igual na minha família quando eu falei, eles estavam apavorados, ELES ESTAVAM A-PA - VO - RA - DOS. Tipo assim [...]parecia que eu tava indo para um, gente parecia que eu tava indo pra jaula do leão[...] não parecia que a gente tava indo lidar com seres humanos.

A postura da família de Lourdes traz os preconceitos socialmente construídos com relação aos sujeitos privados de liberdade. Segundo Buendgens e Carvalho. (2016) os preconceitos são produzidos na vida e dos pensamentos cotidianos e decorrentes de pensamentos ultrageneralizados, o que se configura quando assumimos estereótipos e esquemas já elaborados que são impingidos pelo meio em que crescemos e nos formamos. Sobre isso temos também a fala de Helena:

Helena: Neste quesito de não humano tal. Eu cheguei a comentar com alguns parentes, amigos que eu fui e muitos deles falavam: Nossa oh que legal, tipo queria muito conhecer um presídio, e teve outros que falavam nossa que loucura você vai lá, tipo eles não deveriam ter esse tipo de lazer porque eles tipo fizeram coisa errada.

Helena evidencia alguns desafios para confirmação da educação como um direito humano, portanto universal, e da execução penal como oportunidade para o acesso e produção de conhecimentos que potencializem a busca da autonomia. Os parentes e amigos de Helena indicam que o cumprimento da pena deve ser pautado pelo sofrimento, ou castigo, não aprovando o acesso ao que classificam como "lazer".

Cabe retomarmos que o acesso ao conhecimento e a educação, seja formal ou não formal, é um direito de todos. Onofre e Julião (2013) apontam para a necessidade de compreendermos que 
a educação é um direito universal, garantido pela constituição federal e pela lei de execução penal é deve ser respeitado. Dias (2017) pontua que no Brasil a educação continua sendo pensada como privilégio de poucos mesmo que formalmente ela seja prevista como um direito.

Segundo Buendegens e Carvalho (2016), a produção de preconceitos decorre da cristalização das formas necessárias da estrutura do pensamento da vida cotidiana e isso faz com que os indivíduos tenham reduzidas suas margens de movimentos, acarretando assim a alienação. Assim como a alienação a produção dos preconceitos é determinada pelo sistema, pela hierarquia da sociedade e pelo lugar que o indivíduo ocupa nesta. Sabemos que os sujeitos privados de liberdade ocupam majoritariamente um lugar de rejeição e preconceito. Temos um excerto interessante para refletimos sobre o assunto:

Kaique: É que tem no senso comum que a cadeia a função dela é castigar...não é reintegrar.

Ainda que contrarie a função oficialmente definida para a prisão, que é a ressocialização dos indivíduos, Kaique percebe que o senso comum clama pelo castigo. Segundo Dias (2017) para, ao mesmo tempo, atender à demanda pelo castigo e também estimulá-la, o sistema de justiça brasileiro tem intensificado a política de encarceramento em massa.

Apoiada sobre a disseminação do sentimento de insegurança e medo, a política de encarceramento em massa ganha o apoio da população em geral, ampliando os grupos selecionados para o aprisionamento, e vitimizando, sobretudo a juventude negra, com baixa escolaridade, conforme apontam os dados apresentados anteriormente.

A teoria histórico cultural aponta para o fato de que nada no mundo social é natural. A nossa proposta de análise buscou desnaturalizar as falas e compreender quais são as possibilidades que os nossos sujeitos tiveram, ao longo da sua vida, para se constituírem como tal. Pode-se, então, afirmar que o ser humano não nasce humano, ele torna-se humano, que se constitui enquanto sujeito pelas suas relações e vivências.

\section{Considerações finais}

A teoria histórico cultural de Vigostski (2007) aponta que a aprendizagem depende das interações ocorridas nos diferentes contextos, seja na educação formal ou não formal. De acordo com a perspectiva dialógica entendemos que os significados que damos à realidade social foram criados em interações, não são apenas dados pelos sistemas, nem saem prontos de nosso interior. 
Mas, tanto o sistema como nosso interior foram configurados a parti das nossas interações sociais. As interações e relações dialógicas, onde é favorecido um diálogo no qual estão representadas mais vozes e em maior igualdade de condições de serem educadas e valorizadas, impactam positivamente todos os participantes, no caso os mediadores e os educandos privados de liberdade.

A difusão científica mostra-se, atualmente, como importantíssimo instrumento para consolidar a democracia e evitar que o conhecimento seja sinônimo de dominação e poder (PORTO, 2011). A ciência e a tecnologia são patrimônios da humanidade e a população deve ter acesso a esse conhecimento. Seus efeitos e prejuízos serão divididos com todos, apesar de os benefícios, hoje, estarem restritos a apenas alguns. Pensando nessa dificuldade de acesso à educação nas prisões, acarretada por diversos fatores, essas atividades de difusão cientifica e popularização da ciência realizadas por meio da educação não formal tiveram como objetivo aproximar esse segmento social do conhecimento científico, levando esse conhecimento para um ambiente onde até mesmo a educação formal, que é garantida por lei ocorre de maneira escassa e, algumas vezes, precária.

Em nossa experiência, verificamos indícios objetivos de que participar desse processo interativo de difusão científica na educação não formal, Banca da Ciência, com os educandos privados de liberdade permitiu uma aproximação que trouxe contribuições na formação dos mediadores, que são futuros professores, fazendo-os refletir sobre as especificidades do trabalho com o público da EJA e, além disso, levou-os a pensar o papel da difusão científica e da educação não formal no processo de aproximação da população, inclusive a carcerária, do conhecimento científico.

\section{Referências}

AGUIAR, Wanda Maria Junqueira; OZELLA, Sergio. Núcleos de significação como instrumento para a apreensão da constituição dos sentidos. Psicol. cienc. prof. [online], São Paulo, v. 26, n. 2, p. 222-245, 2006.

ARROYO, Miguel G. Passageiros da noite: do trabalho para a EJA: itinerários pelo direito a uma vida justa. Petrópolis, RJ: Vozes, 2017.

AUBERT, Adriana.; FLECHA, Ainhoa; GARCIA, Carme; FLECHA, Ramón; RACIONERO, Sandra. Aprendizagem dialógica na sociedade de Informação. São Carlos: Edufscar, 2018.

BRASIL. Conselho Nacional de Educação (CNE). Parecer CNE/CEB no 11, de 10 de maio de 2000. Diretrizes curriculares nacionais para a educaşão de jovens e adultos. Brasília: CNE, maio 2000. 
BUENDGENS, Jully Fortunato; CARVALHO, Diana Carvalho de. O Preconceito e as Diferenças na Literatura Infantil. Educ. Real., Porto Alegre, v. 41, n. 2, p. 591-612, jun. 2016.

CAZELLI, Sibele., MARANDINO, Martha., STUDART, Denise. Educação e Comunicação em Museus de Ciências: aspectos históricos, pesquisa e prática In: GOUVÊA, Guaracira: MARANDINO, Martha; LEAL, Maria Cristina (Orgs.). Educaşão e Museu: a construção social do caráter educativo dos museus de ciências. Rio de Janeiro: FAPERJ, Editora Access, 2003.

CURY, Carlos Roberto Jamil. Parecer CNE/CEB 11/2000 que dispõe sobre as diretrizes curriculares para a educação de jovens e adultos. Brasília: MEC, CNE, 2000. Disponível em: http://portal.mec.gov.br/cne/arquivos/pdf/pceb011_00.pdf.

GOHN, Maria da Glória. Educação não formal e cultura política: impactos sobre associativismo do terceiro setor. $5^{\circ}$ ed. São Paulo: Ed. Cortez, 2011.

DIAS, Camila Caldeira Nunes. Encarceramento, seletividade e opressão: a crise carcerária como projeto político. São Paulo: Friedrich Ebert Stifung Brasil, 2017 (Análise)

FREIRE, Paulo. Pedagogia da Esperança: um reencontro com a Pedagogia do Oprimido. Rio de Janeiro: Paz e Terra, 1999.

FREIRE, Paulo. Pedagogia do Oprimido. 60 ed. Rio de Janeiro: Paz e Terra, 2016.

FREIRE, Paulo. Pedagogia da Autonomia: saberes necessários à prática educativa. 25 ed. São Paulo: Paz e Terra, 2017.

FREIRE, Paulo. Extensão on Comunicaşão. 19 ed. São Paulo: Ed. Paz e Terra, 2018.

GALVÃO, Ana Maria de Oliveria.; DI PIERRO, Maria Clara. Preconceito contra analfabeto. São Paulo: Cortez, 2007.

GRACIANO, Mariângela.; HADDAD, Sérgio. O direito humano à educação de pessoas jovens e adultas presas. Conjectura: Filos. Educ., Caxias do Sul, v. 20, n. especial, p. 39-66, 2015.

NÓVOA, António. Firma a posição como professor, afirmar a profissão docente. Cadernos de pesquisa, São Paulo, v. 47, n. 166, p. 1106-1133, 2017.

ONOFRE, Elenice Maria Cammarosano; JULIÃO, Elionaldo Fernandes. A educação na Prisão: como Política Pública: entre desafios e tarefas. Educação \& Realidade, Porto Alegre, v. 38, n. 1, p. 57-69, 2013.

PIASSI, Luis Paulo de Carvalho; SANTOS, Caynnã de Camargo; SANTOS, Emerson Izidoro. Ciência e Comunicação: a divulgação científica através de artefatos culturais no projeto 'Banca da Ciência'. In: XXXVI Congresso Brasileiro de Ciências da Comunicaşão, 2013, Manaus, AM. Anais do Congresso Brasileiro de Ciências da Comunicação. São Paulo, SP: Sociedade Brasileira de Estudos Interdisciplinares da Comunicação, 2013. v. 36. 
PORTO, Cristiane de Magalhães. Um olhar sobre a definição de cultura e de cultura científica. In: PORTO, Cristiane; BROTAS, Antonio; BORTOLIERO, Simone (Orgs.). Diálogos entre ciência e divulgação científica: leituras contemporâneas. Salvador: EDUFBA, 2011.

TRILLA, James. A educação não formal. In: TRILLA, J., GHANEM, E.; ARANTES, V. A. (org.); Educação formal e não formal: pontos e contrapontos. São Paulo: Summus, 2008.

VIGOTSKI, Lev Semyonovich. A Formação Social da Mente. São Paulo: Martins Fontes, 2007.

Recebido em: 28 fev. 2020 / Aprovado em: 15 abr. 2020

\section{Cite como (ABNT NBR 6023:2018)}

VERSOLATO, Marina Savordelli; ALVES Ana Paula Moreira; IZIDORO, Emerson. Ciência na prisão: educação não formal e a formação inicial docente no contexto prisional. Dialogia, São Paulo, n. 34, p. 122-138, jan./abr. 2020. Disponível em: https://doi.org/10.5585/Dialogia.N34.16659. 